\title{
É TUDO VERDADE! \\ TESTEMUNHO E EXPERIÊNCIA EM O PRISIONEIRO DA GRADE DE FERRO (AUTORRETRATOS)
}

\author{
Nilcéia Valdati*
}

\begin{abstract}
Resumo: Como a tentativa de biografar-autobiografar-testemunhar a experiência do confim prisional produz indagações sobre as formas de ler, narrar, montar? A questão surge a partir da constatação de um fenômeno cada vez mais evidente nos últimos anos, a existência de uma grande quantidade de produções, cinematográficas, literárias, que têm como foco contar a experiência do cárcere. Um exemplo disso é o filme O prisioneiro da grade de ferro (autorretratos), de 2003, dirigido por Paulo Sacramento, que, através de um experimento cinematográfico, o de colocar nas mãos dos detentos uma câmera filmadora, procura documentar a rotina dos últimos meses do-no Carandiru. O que nos interessa aqui, percorrendo a esteira benjaminiana, é perceber como esse tipo de produção coloca lado a lado as categorias experiência e testemunho; como, em certo sentido, a experiência enquanto experimento toca o testemunho.
\end{abstract}

Palavras-chave: Experiência. Testemunho. Confim. Narração. Cinema Documentário.

\begin{abstract}
Não é "a verdade" ou "a mentira" que interessam, o imaginário é o que me interessa, quando a pessoa fala que incorpora um santo e incorpora, se conta bem contado, se sabe contar, me interessa. Vira verdade. Se a gente não conhece o imaginário do povo como vai querer mudar alguma coisa? Eu cito Deleuze, quero "pegar o outro em flagrante delito de fabulação".

Eduardo Coutinho
\end{abstract}

O que devemos fazer com nossas imaginações? Amá-las, acreditar nelas a ponto de as devermos destruir, falsificar [...]

Giorgio Agamben, Profanações

NARRAR A-NA-DA' PRISÃO

Poeira. Silêncio. Textos informativos. Retrocesso da imagem. Três, dos nove pavilhões da Casa de Detenção Professor Flamínio Fávero, do Complexo Penitenciário do Carandiru, são recompostos. Assim inicia-se a montagem de $O$ prisioneiro da grade de ferro (autorretratos). O filme, dirigido por Paulo Sacramento ${ }^{2}$, começa a ser

\footnotetext{
* Doutora em Literatura pela Universidade Federal de Santa Catarina (UFSC). Professora de Literatura Brasileira na Universidade Estadual do Centro-Oeste (UNICENTRO). E-mail: valdati@gmail.com.

${ }^{1}$ Opto por usar o hífen entre os três elementos que regem a ação de narrar, e também em vários outros momentos da sequência do texto, por identificar no hífen um jogo dialético, o qual segundo Agamben "une só na medida que distingue e vice-versa." (AGAMBEN, 2000, p.171)

${ }^{2}$ Paulo Sacramento é formado em cinema pela Eca/Usp, dirigiu os curtas Ave, em 1992, e Juvenília, em 1994. Foi assistente de direção de Sérgio Bianchi no filme $A$ causa secreta, de 1994. Fez a montagem de Tônica Dominante, de 2000, de Lina Chamie, de Cronicamente Inviável, 2000, Quanto vale ou é por quilo, 2005, de Sérgio Bianchi. Produziu e montou o longa-metragem Amarelo Manga, 2002, de Cláudio
} 
configurado a partir do momento em que o diretor e uma equipe de pessoas que trabalham com cinema ministram, durante sete meses, oficinas de vídeo para os detentos do Carandiru. Enquanto resultado deste trabalho, aos participantes, é dada a tarefa de, com a câmera na mão, filmar o cotidiano dos últimos meses da Casa de Detenção. É 2001, e a câmera, ora na mão de detentos, ora não, passa por todos os nove pavilhões, escolhe personagens, ambienta o espaço, cronometra as ações, expõe a rotina, enfim, explica a organização daquela comunidade carcerária.

A produção e a distribuição de $O$ prisioneiro da grade de ferro (autorretratos) coincidem $^{3}$ com a de um outro, que também tenta mostrar o cotidiano do mesmo complexo penitenciário. É Carandiru, dirigido por Hector Babenco, baseado no livro homônimo de Drauzio Varella. A existência desses dois filmes (e do livro) se junta a outras escritas que surgem naquele mesmo momento e que procuram narrar a experiência prisional por diferentes possibilidades, diferentes ângulos, diferentes olhares: a escrita de dentro da prisão, a de fora dela; a escrita de si e a escrita do outro. É o caso dos livros: Memórias de um sobrevivente ${ }^{4}$ (2001), de Luiz Alberto Mendes; Enjaulado: o amargo relato de um condenado pelo sistema penal ${ }^{5}$ (2002), de P. Negrini; Sobrevivente André du Rap, do massacre ao Carandiru' (2002), de André du Rap.

Em todas essas produções, a tentativa é a de exercer a narração, na qual a tarefa de biografiar, autobiografar, testemunhar e ficcionalizar se encontra e se desencontra no instante mesmo da construção de uma vida. Em $O$ prisioneiro da grade de ferro (autorretratos), produção que é foco deste trabalho, o narrar a-na-da prisão pode ser traduzido como possibilidade desse confim ${ }^{7}$ ser narrável, ser passível de elaboração de imagens. Se esse confim toma forma, é porque há nele alguém que ali se vê. Alguém que atrai o olhar daquele que está para além do confim, ou fora dele. Nesse sentido, quando direciono o olhar para tal produção cinematográfica, penso em como a questão da experiência, tão cara à tradição crítica benjaminiana, relaciona-se ao testemunho, e este, por sua vez, torna-se um "campo minado" por uma série de elementos biográficos, autobiográficos e ficcionais.

Assis. Produziu e montou junto com José Eduardo Belmonte A concepção, em 2005. Estreou no cinema de ficção em 2013, com roteiro, produção, direção e montagem de Riocorrente.

${ }^{3}$ Em entrevista a Rodrigo Capella, Paulo Sacramento afirma que não assistiu ao filme de Babenco e que os dois realizaram os respectivos filmes sem qualquer troca ou influência de ambas as partes. (Disponível em < cineminha.com.br $>$ Acesso em: 12 set. 2014).

${ }^{4}$ Luiz Alberto Mendes narra de dentro da prisão a experiência, principalmente, dos mais de 30 anos em que lá ficou enquanto detento.

${ }^{5} \mathrm{O}$ advogado e criminalista Pedro Paulo Negrini narra a vida do presidiário Rogério Aparecido, desde sua condenação até a liberdade, através de depoimentos do condenado.

${ }^{6}$ André du Rap, sobrevivente do Massacre do Carandiru, em colaboração com o jornalista Bruno Zeni, narra os momentos vividos por ele na penitenciária.

${ }^{7}$ Quando utilizo a categoria confim, penso na diferenciação que Massimo Cacciari (2000) faz entre limes e limen. Para Cacciari, enquanto o limen é a soleira, é a "passagem" através da qual se penetra um domínio ou se sai dele, o limes limita, circula, cerca esse mesmo domínio. Nesse sentido, a palavra confim, ao se referir ao espaço da prisão, coloca essa relação de tocar e afastar, encontrar e desencontrar e vice e versa. 
2001. Casa de Detenção. Xadrez 2309. Nele, o detento Celso faz o café. Explica como é estar naquele lugar, naquela situação: "Muita coisa vai mudar na vida de quem passa por essa experiência [...] O pior é o sofrimento do isolamento". Vários presos se apresentam: nome, pavilhão, prontuário, artigo. No momento em que se ouve a fala de cada um deles, se vê na tela uma fotografia da ficha policial, e nela uma placa com as informações: entrada, prontuário, artigo.

Pavilhão 8. Kric e FW andam em direção ao pavilhão, com uma câmera na mão, cantando um rap. Um jogo de futebol e a imagem trêmula, desfocada, começa a acompanhar a bola e a desviar o ângulo: o chão, a trave, o outro jogador, o pavilhão. Nessa sequência de cenas se observa a presença de duas câmeras, de dois olhares, de uma dupla forma da montagem, ou seja, percebe-se a câmera que registra a outra que olha. Ou ainda, a forma da montagem explicita que há um olhar no olhar da filmagem. O olhar de quem está de fora do sistema penitenciário e daquele que está inserido nele. Essa é a singularidade utilizada na montagem de $O$ prisioneiro. Singularidade que leva à indagação de como a estratégia de dar espaço ao documentado se mostrar, se narrar, coloca-se dentro do cinema documentário.

A resposta, embora não objetiva e pontual, caminha para se pensar um pouco sobre a tradição brasileira de criação cinematográfica documental. No Brasil, um dos nomes mais ressoantes é o de Eduardo Coutinho, que a partir dos anos 1970 se tornou o ícone desta maneira de se fazer cinema e televisão. Consuelo Lins, que trabalhou diretamente com o cineasta ${ }^{8}$, ao analisar a produção do mestre, esclarece:

\begin{abstract}
A possibilidade de "filmar o que existe", ou de aceitar "tudo o que existe pelo simples fato de existir", é um dos efeitos dos dispositivos de Coutinho. É verdade que essas frases do diretor - dentro de um contexto documental atravessado pela crença na transposição do real para a imagem - provocam mal-entendidos, porque podem sugerir que ele filma a realidade "tal qual ela é", ou que se conforma com o mundo como ele se apresenta: injusto, cruel e desigual. Nada mais oposto ao cinema de Coutinho. O que esse pensamento expressa é um desejo de se esquivar das idealizações que impedem justamente uma aproximação mais afetiva com o que nos cerca. É um movimento que desloca teorias, crenças, interesses, preconceitos, pontos de vista prévios, sentimentos piedosos, culpas e toda a sorte de clichês visuais e sonoros que aderem a nossa percepção e nos fazem acreditar que conhecemos o mundo. Trata-se de uma prática que se atém, na medida do possível, ao material oferecido pelo universo a ser filmado - uma favela, um prédio, um morro, um depósito de lixo -, imprimindo aos filmes uma espécie de imanência radical, em que ética e estética se articulam de modo inextricável. (LINS, 2004, p.12).
\end{abstract}

As considerações que Consuelo Lins faz acerca do trabalho de Coutinho nos levam a pensar sobre a montagem a partir da denominação autorretratos em $O$ prisioneiro. A princípio, há indícios de uma "autobiografia coletiva" de pessoas que estão de passagem pelo mesmo lugar, ou de pessoas que testemunham situações diferentes dentro de um mesmo espaço de reclusão. No entanto, há um colocar-se em

\footnotetext{
${ }^{8}$ Consuelo Lins trabalhou com Eduardo Coutinho em Babilônia 2000, de 2001, e Edifício Master, de 2002 .
} 
jogo, em que tanto os detentos que colhem imagens, quanto a equipe de direção que faz as montagens, participam deste movimento. No instante em que a câmera é dada aos prisioneiros para que esses escolham o que desejam mostrar do Carandiru, o diretor "concede" ao detento a oportunidade de atestar que forma de vida, que experiência é possível ser inventada a partir da condição de confinamento. Porém, o ato da concessão só é permitido porque há naquele grupo a vontade de falar, de filmar, de narrar. Do contrário, o jogo não se montaria.

Ainda sobre a relação entre o cineasta e o filmado, Jean-Claude Bernardet (2003, p.09) assegura:

\begin{abstract}
Para que o povo esteja presente nas telas, não basta que ele exista: é necessário que alguém faça os filmes. As imagens cinematográficas do povo não podem ser consideradas sua expressão, e sim a manifestação da relação que se estabelece nos filmes entre os cineastas e o povo. Essa relação não atua apenas na temática, mas também na linguagem.
\end{abstract}

A linguagem, fazendo uso do termo utilizado por Bernardet (2003), a estética e a ética, atribuídas a Coutinho, nas palavras de Lins (2004), caminham para se pensar na opção pela forma de montagem de $O$ prisioneiro. De um lado, a de deixar que o próprio objeto se filme, se monte, de outro, a de retirar a participação do objeto (os detentos) na montagem final. O próprio Sacramento (2004), em entrevista a uma revista semanal de ampla circulação, afirma:

\begin{abstract}
Pensei em montar uma parte com eles, no presídio, mas isso ficou inviável. Iria demorar demais. Não tenho como mostrar material para todos os filmados e escutar a opinião deles sobre como querem aparecer. Alguém tem de tomar decisões se não o filme nunca acaba. $\mathrm{E}$ essa decisão tem de ser do diretor. O filme tem uma lógica própria. Essa está acima de minhas vontades, assim como dos desejos de quem é filmado. A verdade é a seguinte: todo mundo está sujeito a se dar mal em documentário. Existe uma parcela de risco que todos têm de correr. (SACRAMENTO, 2004, s.p).
\end{abstract}

Paulo Sacramento, ao assumir o lugar da direção; Eduardo Coutinho, ao constatar a fabulação 9 enquanto elemento de composição do documentário; Bernardet, ao reivindicar a necessidade da relação entre o cineasta e o povo, colocam à baila o que Giorgio Agamben (1998a) atesta ao analisar o cinema de Guy Debord. Diz o filósofo italiano que a técnica composicional nunca muda, é sempre montagem e por causa dela o cinema entra em uma zona de indiferenciação, na qual todos os gêneros tendem a se coincidir, o documentário e a narração, a realidade e a ficção, ou seja, para Agamben (1998a, p.69), o cinema é feito a partir das imagens do cinema, é imagem da imagem, e do que se faz com elas, acrescenta em "Os seis minutos mais belos do cinema" (2005a), em menção a uma sequência da filmagem incompleta de Dom Quixote, por Orson Wells. $^{10}$

\footnotetext{
9 Refiro-me à primeira epígrafe deste texto, retirada de entrevista de Eduardo Coutinho, concedida a Angélica Valente, em 2001.

${ }^{10}$ Situo nesse momento a segunda epígrafe do texto, retirada de um pequeno ensaio de Giorgio Agamben "I sei minuti piú belli della storia del cinema" (2005a).
} 
Fim de tarde. Um prisioneiro olha a cidade pela grade de ferro, enquanto no rádio toca a "Ave-Maria". O tom de melancolia surge com as imagens do presídio, principalmente as de grades. Dia seguinte. Inclusão. A calça, modelo único. Palestra da triagem. O agente prisional que recebe os novos detentos coloca duas certezas. Primeira: "Os senhores estão presos"; segunda: "Os senhores vão sair".

A cachaça, a Maria Louca. O processo de destilação. A maconha. Uma planta da erva. Mãos de presos embrulhando balas de maconha. Preço: 1 real. Falas: "O passatempo da cadeia é isso aqui [...] Filmando o que é [...] Pra sociedade isso é um mal, mas pra gente é uma paz." O craque. "A raspa da canela do diabo [...] Só vendo fiado, recebo no fim de semana [...] Droga na cadeia é luxo." O autor dessas falas segura nas mãos dois facões, não se vê o rosto. As armas. Um detento explica a fabricação: "A cadeia é feita de cimento e ferro". Mais uma vez a Ave-Maria, imagens de rostos de presos por meio do pequeno quadrado da porta da cela.

A montagem dessas sequências, construídas através do corte, da repetição e da simultaneidade, ocorre porque no intervalo entre a primeira e a segunda certeza (da fala do agente penitenciário) há o desejo, como já foi explicitado anteriormente, de contar, de narrar, de se expor, isto é, de olhar o passado de cada dia na constituição de uma rotina do presente. Se partirmos da afirmação de Agamben (1998a) de que a montagem é o que está em primeiro plano, cabe considerar que o que chamamos de experiência a partir do filme $O$ prisioneiro da grade de ferro (autorretratos) se confunde com a técnica, se confunde com o experimento de colocar a câmera nas mãos dos presos para captação de imagens. Imagens que são acompanhadas por longos espaços de silêncios da fala, preenchidos, no entanto, pelos sons do rádio, da música, do aparelho de tatuagem, dos raps.

A fala é mínima. Praticamente não há fala, e quando esta ocorre não traz em si novidades. Ela acontece, muitas vezes, quando a imagem não pode ser identificada; é o caso, por exemplo, de quando são apresentadas as armas e as drogas. Nesse sentido, para haver experiência, o experimento da imagem montagem entra em cena. A imagem, enquanto resultado do artifício da montagem, ganha espaço para produzir os efeitos que Walter Benjamin, em outro momento histórico, atribuía à fala, à oralidade.

Em "Experiência", de 1913, texto escrito pouco antes da Primeira Guerra Mundial, Benjamin enxerga na atitude do adulto a máscara da experiência. "Ela é inexpressiva, impenetrável, sempre igual. Esse adulto já experimentou tudo: juventude, ideais, esperanças, a mulher. Tudo foi ilusão." (BENJAMIN, 1984, p.23). Em "Experiência e pobreza", de 1933, observa que os jovens soldados que participaram da Primeira Guerra Mundial voltaram do campo de batalha silenciosos (BENJAMIN, 1994, p.115). O que fazer com o passado? Como pensar a história? Como significar o por vir? São as perguntas lançadas por Benjamin e para as quais muitos outros teóricos se voltaram na tentativa de compreender os sintomas contemporâneos (como o caso da existência de uma quantidade enorme de produções que procuram contar a experiência da prisão). 
Giorgio Agamben (2005b), leitor de Walter Benjamin, em Infância e história: ensaio sobre a destruição da experiência, texto de 1978, em trecho em que se refere à "Experiência e pobreza", afirma que não é necessário que ocorra uma catástrofe mundial para que haja o emudecimento, a destruição da experiência; a existência cotidiana, de uma grande metrópole, se encarrega disso. "Pois o dia-a-dia do homem contemporâneo não contém quase nada que seja traduzível em experiência" (AGAMBEN, 2005b, p.22). Acrescenta que a experiência se coloca hoje fora do homem, que a olha com alívio. Ela se coloca nos museus, nos pontos de peregrinação (cabe acrescentar: nas ruínas de um complexo penitenciário). Há uma recusa em experimentá-la, o homem prefere que a máquina fotográfica (mais um acréscimo: a câmera de filmagem) tenha a experiência que seria a dele. Se, por um lado, Benjamin e Agamben atestam a destruição da experiência, por outro, acreditam na possibilidade da maturação do germe da experiência através da "filosofia que vem".

Experiência concebida no intervalo e no lapso da vivência individual (Erlebnis) e seu compartilhar coletivo (Erfahrung), são as palavras de Benjamnin (1994), retomadas por Pablo Gonçalo (2011), ao analisar três documentários, aos quais dá a denominação de subjetivos: Rua de mão única (Cao Guimarães, 2002), Jogo de cena (Eduardo Coutinho, 2006), Serious Games (Harum Farocki, 2010). Nesses documentários, Gonçalo (2011) vê que a subjetividade enquanto experiência coloca em jogo a relação entre linguagem, ética e produção audiovisual:

\footnotetext{
Seja na representação de si, seja na representação do outro ou mesmo na análise de traumas psicológicos, são propriamente documentadas faces do processo de construção subjetiva. Processos frágeis, incipientes e incompletos. Esses documentários de lançam na aventura de (des)construir discursos de subjetividades, que, portanto revelam-se solventes. São jogos com o sujeito; jogos subjetivos, ou apenas filmes que propõem novas dinâmicas na relação entre a subjetividade e a experiência audiovisual.
}

A palavra e a imagem são, pelo que vimos até esse momento do trabalho, a possibilidade da experiência romper o seu lugar de silenciamento e cegueira através do experimento audiovisual. De potencializar o cotidiano passado para significar o agora e inscrever um lugar no depois. É nesse sentido que a experiência se liga ao tempo e, por sua vez, à história. As montagens de $O$ prisioneiro também caminham nessa perspectiva a partir do momento em que se propõem a registrar um cotidiano, que dentro de poucos meses será ruína. O confim Carandiru não existirá mais, e antes que ele se transforme em monumento, são registradas as últimas imagens que dele podem ser montadas por meio das experiências dos que lá vivem.

\section{EXPERIENCIAR-TESTEMUNHAR}

Nas celas. Romualdo esculpe. Lenno talha na madeira: "A minha inspiração não é o que vejo aqui dentro". Carlos desenha paisagens. Adilson desenha em bico de pena: "Desenho lugares que eu gostaria de estar". No pátio. Dia de visita. O fotógrafo registra cenas de colegas com familiares. Fotografa também os corpos dos que foram mortos na 
prisão. Fotos de corpos ensanguentados, esfaqueados. "Fotografei com os familiares, logo em seguida, tenho que fotografar ele esfaqueado [...] Existe um código de ética. Errou, paga com a vida".

Enquanto o trabalho dos quatro primeiros se coloca como a armadilha que encontram para "fugir" daquele confim, a do segundo é o registro do que de mais extremo aquele lugar produz: a morte, transformada em criação nas fotografias que são expostas no filme e geradora de um outro confim, o da experiência do corpo. Como nos lembra Franco Rella (2004), a morte é uma das experiências do corpo, principalmente para a literatura, a filosofia, as artes figurativas e os eventos ético-políticos e pessoais.

Ainda na esteira benjaminiana, Márcio Seligmann-Silva (2003), em $O$ testemunho: entre a ficção e o real, ao analisar as produções literárias de testemunho, destaca que a diferenciação dessas produções das chamadas narrativas realistas é a relação que elas assumem com a chave freudiana do trauma, "de um evento que justamente resiste à representação" (SELIGMANN-SILVA, 2003, p. 377). Para esclarecer esta ideia, coloca que em latim o testemunho pode ser denominado através de duas palavras: o testis e o superstes. "A primeira indica o depoimento de um terceiro em um processo." E a segunda "indica a pessoa que atravessou uma provação, o sobrevivente." (SELIGMANN-SILVA, 2003, p. 377-378). A relação entre testis e superstes traz duas condições para se pensar o testemunho. De um lado, o testemunho como terceiro "traz à luz o fato de que o testemunho por definição só existe na área enfeitiçada pela dúvida e pela possibilidade da mentira", de outro, "a acepção de testemunho como sobrevivente [...] indica a categoria excepcional do 'real' que o testemunho tenta dar conta a posteriori." (SELIGMANN-SILVA, 2003, p. 377-378).

Os dois termos utilizados por Seligmann-Silva (2003) são tomados das considerações que Agamben (1998b) faz sobre a testemunha, em Quel che resta di Auschwitz. Porém, o filósofo italiano, ao analisar neste livro os relatos dos que voltaram do campo de concentração - experiência distinta da prisional, no Brasil, hoje -, coloca, além da testemunha, uma outra categoria, a do muçulmano. Aquele que não consegue testemunhar, o que se submete à vontade de um outro. A explicação mais provável para essa designação, segundo Agamben (1998b), refere-se ao significado literal do termo árabe muslim, que significa "aquele que se submete incondicionalmente à vontade de Deus".

O mulçumano é aquele que viu o olhar da medusa, que Primo Levi (2005) apresenta em seus relatos: aquele que viu a Gorgona, mas que não voltou para contar, ou voltou mudo. É ele, para Levi (2005), a testemunha integral. Esse exemplo é citado tanto por Agamben (1998b) quanto por Seligmann-Silva (2003). Ambos concordam que nesse ponto reside o problema do testemunho: aquele que chega à experiência limite não consegue narrar esta situação, porque o corpo não sobreviveu para tocar o trauma. Entretanto, pelo silenciamento, ou pela morte do corpo, o mulçumano se torna a figura que constitui a destruição da experiência. Para ele não há tempo, não há história. A testemunha, que assim se torna pela própria vontade de narrar a experiência do confinamento, sobrevive para contar a sua e a do outro. Desta forma, o por vir traz à tona a implicação entre testemunho e experiência, ou seja, há testemunho se há experiência, se há disposição para tocar o trauma. 
A professora Shoshana Felman (2000), em Educação e crise, ou as vicissitudes do ensinar, como Agamben e Seligmann-Silva, acredita que a vontade de testemunhar faz com que o confinado sobreviva. No texto, ela narra como foi a experiência de colocar o testemunho enquanto prática pedagógica. Para isso organizou um curso em torno de temas literários, psicanalíticos e históricos em que o foco era o testemunho, tendo como objetivo não o estudo analítico, mas, de maneira geral, fazer com que os alunos sentissem a experiência do trauma.

A experimentação pedagógica da professora Felman e a experimentação da montagem de $O$ prisioneiro caminham lado a lado enquanto maneiras de lidar com a própria história, com a construção de si, de poder olhar para si, fora de si. Dessa maneira, as duas condições de fala e de imagens dos artistas na prisão - aqueles em que a inspiração está fora daquele lugar e o fotógrafo que registra o encontro familiar e os corpos dos mortos - produzem o mesmo efeito: ambos buscam "sobreviver". Mesmo que não seja o do campo de concentração, a prisão também coloca a vida em jogo, coloca-a no limite.

\section{TESTEMUNHAR-NARRAR}

O ano de 2002 marcou o fim da Casa de Detenção. Mais de 7.000 presos foram dali removidos para novas unidades prisionais e os Pavilhões 6, 8 e 9 foram implodidos em ato público comandado pelo governador do Estado. As últimas imagens são depoimentos de ex-diretores da casa de detenção. Em geral, expõe as péssimas condições do sistema carcerário no Brasil. Um deles diz: "A cadeia não recupera ninguém. Só isola da sociedade."

A poeira, que no início do filme impossibilitava a clareza do olhar, trazia as incertezas, cobria a tentativa de narrar, colocava uma atemporalidade, é a mesma poeira que acompanha o testemunho e a experiência, que coloca hífens, que estreita limes e limen que compõem o confim, que agrupa mulçumano e testemunha, que brinca com o real e a ficção, que cobre a montagem com os seus espessos grãos. Qualquer dia desses, diz Bataille (1969, p.152), a poeira "começará a triunfar sobre as serviçais, invadindo as construções abandonadas, os diques desertos: nessa época longínqua não subsistirá nada que salve dos terrores noturnos, para cuja falta nos transformamos em tão bons contadores..."

A sugestão dada por Bataille está na narração. A poeira que se deposita sobre o que está vazio, paralisado, fixo, consolidado é o elemento que permitirá à narração construir-se. A própria atitude de fazer o filme antes da demolição é uma forma de ainda narrar o que restou daquele lugar a partir da poeira. É da poeira que a montagem vai se construindo, vai dando forma à experiência de algumas vidas naquele confim, vai permitindo que testemunhos sejam falados, imaginados, creditados.

\section{REFERÊNCIAS}

AGAMBEN, Giorgio. A imanência absoluta. Trad. Cláudio William Veloso. In: Gilles Deleuze: uma vida filosófica. São Paulo: Editora 34, 2000. Le cinéma de Guy Debord. In: Image et mémoire. Paris: Editions Hoëbeke, 1998a. 
Infância e história - ensaio sobre a destruição da experiência. In: Infância e história: Destruição da experiência e origem da história. Trad. Henrique Búrigo. Belo Horizonte: Editora UFMG, 2005b. BATAILLE, Georges. Diccionario critico. In: NOEL, Bernard (org.) Documentos. Caracas: Monte Àvila, 1969.

BENJAMIN, Walter. Experiência. In: Reflexões: a criança, o brinquedo, a educação. Trad. de Marcos Vinicius Mazzari. São Paulo: Summus Editorial, 1984.

Experiência e pobreza. In: Magia e técnica, arte e política. Obras escolhidas, vol.1. Trad de. Sérgio Paulo Rouanet. $7^{\mathrm{a}}$ ed. São Paulo: Brasiliense, 1994.

BERNARDET, Jean-Claude. Cineastas e imagens do povo. São Paulo: Companhia das Letras, 2003.

CACCIARI, Massimo. Nomi di luogo: confine. Aut, aut, n.299-300, set-dez 2000.

COUTINHO, Eduardo. Entrevista concedida a Angélica Valente, out. 2001. Disponível em: <www.mnemocine.com.br/arruanda/index.htm>. Acesso em: 20 set. 2005.

DU RAP, André. Sobrevivente André du Rap (do massacre ao Carandiru). São Paulo: Labortexto, 2002.

FELMAN, Shoshana. Educação e crise ou as vicissitudes do ensinar. In: NESTROVSKI, Arthur; SELIGMANN-SILVA, Márcio (orgs.). Catástrofe e representação. São Paulo: Escuta, 2000.

GONÇALO, Pablo. O grau zero da subjetividade: documentários e jogos de linguagem. Crítica Cultural. Palhoça, SC, v. 6, n. 1, p. 233-249, jan.-jun.2011.

LEVI, Primo. Trilogía de Auschwitz - Si esto es um hombre, La trégua, Los hundidos e los salvados. Tradução Pilar Gómez Bedate. 2. Ed. Barcelona: El Aleph Editores, 2005.

LINS, Consuelo. O documentário de Eduardo Coutinho: televisão, cinema e vídeo. Rio de Janeiro: Jorge Zahar Editor, 2004.

MENDES, Luiz Alberto. Memórias de um sobrevivente. São Paulo: Companhia das Letras, 2001.

NEGRINI, Pedro Paulo. Enjaulado: o amargo relato de um condenado pelo sistema penal. Rio de Janeiro: Gryphus, 2002.

RELLA, Franco. Ai confini del corpo. Milano: Feltrinelli, 2004.

SACRAMENTO, Paulo. Entrevista exclusiva com o diretor Paulo Sacramento. Época, n.310, 26 abril 2004. Entrevista concedida a Revista Época. Disponível em $<$ http://revistaepoca.globo.com/Epoca $>$ Acesso em: 20 set. 2005.

Entrevista concedida a Rodrigo Capella. Disponível em <cineminha.com.br $>$ Acesso em: 12 setembro 2005 .

SELIGMANN-SILVA, Márcio. O testemunho: entre a ficção e o "real". In: SELIGMANN-SILVA, Márcio. (org.) História, memória, literatura: o testemunho na era das catástrofes. Campinas - SP: Editora da Unicamp, 2003.

Recebido em 31/03/2015. Aprovado em 16/05/2015.

Title: It's all true! Testimony and Experience in O Prisioneiro da Grade de ferro (Autorretratos)

Abstract: How does the attempt to make a biography-autobiography-testimony of the prisional confine experience engender inquiries on ways of reading, narrating, building? This question arises from the confirmation of the following phenomenon, more evident in the last years: the existence of a large number of literary and cinematographic productions that take as their main focus the narration of prisional experience. An example of this is the 2003 film O prisioneiro da grade de ferro (autorretratos), directed by Paulo Sacramento who, through the cinematrographic experience of putting video camaras in the hands of prisioners, seeks to document the last months' routine of-at Carandiru. What arouses our concern, following Walter Benjamin, is the awareness of how this type of production places erfahrung and testimony side by side; as in a sense that erfahrung (experience) contacts testimony.

Keywords: Experience. Testimony. Confine. Narration. Documentary Film. 